\title{
ACESSIBILIDADE AO CURRÍCULO ATRAVÉS DO USO DO COMPUTADOR PARA ESTUDANTES COM AUTISMO
}

\author{
Mara Monteiro Cruz ${ }^{\mathrm{i}}$ \\ Fabiana Ferreira do Nascimento ${ }^{\text {ii }}$
}

\begin{abstract}
Resumo: O presente artigo se propõe a discutir a utilização de recursos da Informática para promover acessibilidade ao currículo a partir de uma pesquisa de mestrado. A investigação aborda o uso da tecnologia na escolarização de dois estudantes com autismo, em uma escola pública do Rio de Janeiro, no Ensino Fundamental. As atividades realizadas na pesquisa são analisadas tendo em vista os pressupostos sobre acessibilidade ao currículo e Desenho Universal para a Aprendizagem (DUA). Conclui-se que a acessibilidade ao currículo não deve estar pautada em possíveis déficits ou dificuldades dos estudantes, sua concepção deve ser ampla o suficiente para que este considere as características de todo o alunado.
\end{abstract}

Palavras-chave: Acessibilidade ao currículo; Autismo; Informática educativa.

\section{CURRICULUM ACCESSIBILITY THROUGH COMPUTER USE FOR AUTISM STUDENTS}

\begin{abstract}
This article proposes to discuss the use of Information Technology resources to promote accessibility to the curriculum from a master's research. The research addresses the use of technology in the schooling of two students with autism, in a public school in Rio de Janeiro, in Elementary School. The activities carried out in the research are analyzed in view of the assumptions about curriculum accessibility and Universal Design for Learning (UDL). It is concluded that accessibility to the curriculum should not be based on possible students' deficits or difficulties, its conception should be broad enough that it considers the characteristics of all students.
\end{abstract}

Key-words: Accessibility to curriculum; Autism; Educational information technology

\section{Introdução}

Com o avanço das políticas públicas destinadas a efetivar o caráter inclusivo da Educação no Brasil, o foco das discussões tem se voltado para os processos de desenvolvimento e aprendizagem na escolarização do público alvo da Educação Especial.

A presença de estudantes com deficiências e outras diferenças significativas de aprendizagem e desenvolvimento na sala de aula comum, nos dias atuais, muitas vezes denuncia a persistência de um sistema meritocrático, pautado na filosofia do ensino tradicional. Tal sistema se apoia na falsa premissa de padronização dos estudantes segundo critérios como faixa etária, gênero e/ou grupo social. Esta escola ainda não se apropriou da cultura da sociedade da 
comunicação e da informação, uma vez que os recursos tecnológicos são usados apenas como meras ferramentas didáticas a serviço do discurso do professor, quase sempre monólogo.

O currículo, nestes contextos, é compreendido de forma parcial, como conteúdos cujo ensino se depara inexoravelmente com os supostos obstáculos da deficiência, transtorno ou mesmo das altas habilidades. Entretanto, se entendemos que o currículo não é constituído apenas por conteúdos, mas sim por "experiências escolares que se desdobram em torno do conhecimento, em meio a relações sociais, e que contribuem para a construção das identidades de nossos/as estudantes" (MOREIRA; CANDAU, 2007, p. 18), temos pelo menos dois pontos cruciais a considerar: que experiências escolares podem, efetivamente, gerar conhecimento para o estudante público-alvo da Educação Especial; e de que forma a escolarização pode contribuir para a construção da identidade de cidadão que, muitas vezes se vê resumida à condição da diferença, principalmente em se tratando de deficiência, quando estes indivíduos se desenvolvem em meio à segregação e privações culturais (GLAT, 2009).

Refletindo sobre estes pontos, o presente artigo se propõe a discutir a utilização de recursos da Informática para tornar conteúdos curriculares acessíveis a partir de uma pesquisa de mestrado (AUTOR, 2017) sobre o uso da tecnologia na escolarização de dois estudantes com autismo, matriculados em uma escola pública do Rio de Janeiro, nas séries iniciais do Ensino Fundamental.

\section{Autismo e educação}

O autismo, ou Transtorno do Espectro Autista (TEA), de acordo com o Manual Diagnóstico e Estatístico de Transtornos Mentais - DSM-5 (APA, 2014), é um transtorno do neurodesenvolvimento do sujeito. Seus sintomas surgem até os três anos de idade, podendo se manifestar em diferentes níveis de gravidade e áreas de comprometimento, como a aprendizagem, o controle das funções executivas, as habilidades sociais e a inteligência.

É comum a ocorrência de mais algum transtorno associado, como o Transtorno da Atenção/Hiperatividade (TDAH), ou o do Desenvolvimento Intelectual (Deficiência Intelectual), embora a avaliação da função intelectual, nestes casos, possa ser dificultada pelos déficits sóciocomunicacionais e comportamentais inerentes ao quadro clínico (APA, 2014).

Nas edições anteriores do DSM (APA, 1980, 2000), o autismo era compreendido no conjunto dos Transtornos Globais do Desenvolvimento (TGD), motivo pelo qual esta expressão ainda aparece em grande parte da legislação brasileira, como, por exemplo na Lei de Diretrizes e Bases da Educação Nacional (BRASIL, 1996). 
Em 2012 foi promulgada a Lei $n^{\circ} 12.764$ (BRASIL, 2012), específica sobre a garantia dos direitos da pessoa com TEA, definindo-o como uma síndrome clínica caracterizada por um ou ambos os itens a seguir:

\footnotetext{
I - deficiência persistente e clinicamente significativa da comunicação e da interação sociais, manifestada por deficiência marcada de comunicação verbal e não verbal usada para interação social; ausência de reciprocidade social; falência em desenvolver e manter relações apropriadas ao seu nível de desenvolvimento;

II - padrões restritivos e repetitivos de comportamentos, interesses e atividades, manifestados por comportamentos motores ou verbais estereotipados ou por comportamentos sensoriais incomuns; excessiva aderência a rotinas e padrões de comportamento ritualizados; interesses restritos e fixos (BRASIL, 2012, $§ 1^{\circ}$ ).
}

Em relação à escolarização, a referida Lei garante o acesso à educação e ao ensino profissionalizante prevendo multa para o gestor escolar que recusar a matrícula de aluno com TEA e afirmando que "Em casos de comprovada necessidade, a pessoa com transtorno do espectro autista incluída nas classes comuns de ensino regular [...] terá direito a acompanhante especializado" (Art. 3º parágrafo único).

O acompanhante especializado, por vezes chamado de "mediador escolar", é um profissional de grande importância para colaborar no desenvolvimento de estratégias de acesso ao currículo e favorecer o processo de ensino-aprendizagem destas crianças, considerando as prováveis dificuldades nas áreas de interação social, linguagem e/ou comportamento que possuem. Essas questões desafiam a escola cotidianamente quando há estudantes com TEA em turmas comuns.

Nas escolas da rede pública do Município do Rio de Janeiro, os mediadores escolares, quando existem, são estagiários e não necessariamente estão frequentando o curso de Pedagogia. Os professores relatam haver alta rotatividade destes estagiários, uma vez que não possuem vínculo empregatício. Segundo eles, ainda, a interrupção deste trabalho pode gerar consequências emocionais para os estudantes e comprometer o rendimento e acompanhamento do conteúdo curricular (AUTOR, 2017).

Além do mediador escolar, é fato que recursos e estratégias precisam ser adotados e/ou desenvolvidos para que o processo de escolarização seja efetivo para estes estudantes. No entanto, em pesquisa realizada por Nascimento, Cruz e Braun (2016), verificou-se que poucos estudos têm sido realizados nesta área. Entre os 217 artigos sobre autismo publicados na base de dados da Scientific Eletronic Library Online (SciELO) no período de 2005 a 2015, apenas 22 
abordavam a inclusão ou escolarização de pessoas com TEA em ambientes educacionais formais. As autoras organizaram os artigos em categorias segundo os temas abordados:

Quadro 1:

\begin{tabular}{|c|c|c|}
\hline \multicolumn{2}{|c|}{ Estudos sobre autismo } \\
\hline Categorias & Quantidade & Distribuição \\
\hline Práticas pedagógicas & 6 & $27,27 \%$ \\
\hline Percepções e concepções & 3 & $13,63 \%$ \\
\hline Competência social e escolarização & 3 & $13,63 \%$ \\
\hline Linguagem e comunicação & 3 & $13,63 \%$ \\
\hline Historicidade e revisão bibliográfica & 3 & $13,63 \%$ \\
Autobiografia e escolarização & 1 & $4,54 \%$ \\
Recursos tecnológicos e aprendizagem & 1 & $4,54 \%$ \\
Formação de professores & 2 & $9,09 \%$ \\
\hline
\end{tabular}

Fonte: Nascimento, Cruz e Braun (2016)

Em relação ao uso de recursos tecnológicos, observa-se que apenas um artigo foi encontrado (SANTAROSA E CONFORTO, 2015). As autoras analisaram o uso de tecnologias móveis nos anos iniciais do Ensino Fundamental, por três estudantes com TEA e concluíram que o tablet foi o recurso com melhor aplicabilidade, devido às características de mobilidade - pode ser transportado com facilidade para diferentes espaços escolares; além da simplicidade no manuseio, pois o recurso é intuitivo (a partir do toque dos dedos na tela), fornecendo respostas imediatas (feedback).

A pesquisa descrita no presente artigo (AUTOR, 2017) foi desenvolvida em duas fases. Na primeira, realizou-se um estudo de caso instrumental e na segunda a investigação seguiu os pressupostos teórico-metodológicos da pesquisa-ação. Os participantes principais foram dois estudantes do segundo ano do Ensino Fundamental e duas de suas professoras da escola (uma da sala de aula comum e uma do Atendimento Educacional Especializado - AEE); os participantes secundários foram as mães dos alunos ${ }^{\mathrm{iii}}$.

Na primeira etapa, Autor (2017) entrevistou as mães e professoras, além de observar e acompanhar a rotina dos estudantes na sala de aula comum e na sala de recursos multifuncional (SRM), fazendo registros em diário de campo. Essa fase permitiu conhecer a estrutura da escola, os participantes, as atividades desenvolvidas, a interação dos educandos com os recursos didáticos disponíveis, com os colegas de turma e professoras.

$\mathrm{Na}$ segunda fase da pesquisa, Autor (2017) adotou os pressupostos da pesquisa-ação crítico-colaborativa (BRAUN, 2014; JESUS, 2008). Esse tipo de pesquisa tem contribuído para a reflexão crítica (pensamento, elaboração e melhoria da prática) do professor em relação ao 


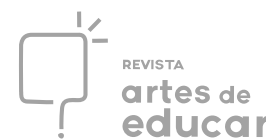

processo de ensino aprendizagem do aluno, favorecendo que, quando necessário, ele o modifique de acordo com as necessidades vigentes.

Nessa fase, a partir da análise dos dados produzidos, e em colaboração com as professoras, foram desenvolvidas atividades usando o computador para promover acessibilidade curricular aos alunos com autismo. A ideia inicial era trabalhar com toda a turma, observando especificamente os alunos público-alvo da pesquisa; mas diante da realidade de haver, na escola, apenas um computador com os recursos considerados necessários (caixa de som, acesso à Internet e aplicativos básicos, como editor de texto), os alunos foram atendidos na SRM ou na biblioteca, de maneira alternada uma vez por semana por aproximadamente três meses.

\section{Acessibilidade ao currículo}

No Brasil, durante pelo menos onze anos (somando-se Educação Infantil e Ensino Fundamental), por, no mínimo vinte horas semanais (no turno da manhã ou tarde), é suposto que a criança e/ou adolescente interaja com as práticas pedagógicas desenvolvidas pelo ambiente escolar ao qual estão vinculados. O ensino, além de projetar as aptidões individuais de cada sujeito que está ali inserido, segundo Perrenoud (2001) é um sistema de ação. Isto significa que busca transformar as pessoas, suas atitudes frente aos acontecimentos e suas representações sobre o que pensam ou sentem. Por isso, além de revelar suas competências, exerce uma influência sobre a sua vida, podendo mudar até os seus gostos.

Um dos instrumentos utilizados pela escola para exercer sua função de poder e para justificar o sucesso ou fracasso escolar é o currículo. Contextualizado de forma padrão, desconsidera as diferenças individuais e se destina a ser, também, padronizador. Segundo Correia (2016) currículo é uma palavra derivada do latim - currere - que significa "corrida" ou "lugar onde se corre". Para o dicionário Aurélio (FERREIRA, 2001) é um substantivo masculino cuja definição é "as matérias constantes de um curso". Neste sentido, é possível compará-lo a uma corrida por adquirir conhecimento através de disciplinas pelas quais obrigatoriamente todas as crianças, adolescentes e jovens vão passar na escola.

Moreira e Candau (2007) explicam que o currículo reflete os modos de educação vigente na sociedade e sua compreensão é determinada pelos fatores socioeconômicos, políticos e culturais. Diante disso pode ser visto pela combinação de cinco concepções: como conteúdos a serem ensinados e aprendidos; como as experiências escolares de aprendizagem; como as propostas pedagógicas das escolas e sistemas educacionais; como processos de ensino; e por 
último pelos processos de avaliação que certamente serão diferentes e irão variar conforme o grau de escolarização.

Defendemos que o educando se apropria do currículo quando consegue incorporar através das suas experiências escolares e das relações sociais estabelecidas, conhecimentos que o ajudam a desenvolver habilidades e construir a sua identidade enquanto cidadão e isso, independente da sua deficiência e/ou de qualquer diferença acentuada nos processos de desenvolvimento.

Quando o aluno público-alvo da educação especial não consegue acompanhar integralmente o currículo proposto, as políticas de educação permitem que sejam realizadas “adaptações curriculares” (BRASIL, 2015). Para Oliveira e Machado (2007) essas adaptações podem ser consideradas como ajustes no currículo de maneira que o mesmo possa atender e acolher as necessidades educacionais de maneira a promover a construção do conhecimento desse aluno. Correia (2016) destaca, entretanto, que alguns pesquisadores não encontram clareza nas leis no que se refere às estratégias de flexibilização ou adequação desse currículo e/ou quais adaptações podem ou não serem realizadas. O que vem se mostrando cada vez mais evidente para a autora é que o termo "adaptações" em alguns estudos pode gerar uma compreensão distorcida recaindo na simplificação das atividades ou esvaziamento do conteúdo, conforme descrito por Efgen (2011), colocando estes estudantes à margem do processo de escolarização, reduzindo ou até mesmo anulando suas possibilidades de aprendizagem.

É importante ressaltar, porém, que a flexibilização do currículo não significa exatamente supressão de conteúdos, como muitas vezes é feita, respaldada pelas baixas expectativas de aprendizagem que podem ser geradas em relação a determinados estudantes. Somente a avaliação continuada poderá indicar que tipos de ajustes são necessários, não só em relação aos conteúdos, mas também na metodologia de ensino.

\section{A acessibilidade ao currículo}

A inclusão educacional depende da implementação de medidas de acessibilidade, sendo este o termo utilizado para reduzir ou eliminar possíveis barreiras, objetivando garantir qualidade de vida para todas as pessoas, independentemente de suas condições. Em relação ao processo de escolarização, para que todos tenham igualdade de condições de acesso e participação nas atividades escolares, é preciso considerar questões como a arquitetura da escola, os meios e formas de comunicação, as metodologias utilizadas, os instrumentos facilitadores no/para o 
cotidiano, as normas e legislações vigentes e as atitudes nas relações sociais (INSTITUTO DE TECNOLOGIA SOCIAL; MICROSOFT, 2008).

A ideia de acessibilidade surgiu na área da arquitetura e foi assumida de maneira normativa a partir da publicação do decreto n. 5.296 (BRASIL, 2004) que utiliza termos como ajudas técnicas (ou tecnologias assistivas) e desenho universal para relacionar produtos, instrumentos e serviços que possam garantir a melhoria da mobilidade de maneira a possibilitar a autonomia pessoal, total ou assistida da pessoa com deficiência.

A Tecnologia Assistiva (TA) tem se afirmado como área multidisciplinar que busca através de suas ações construir estratégias, metodologias, práticas e serviços que favoreçam sua autonomia e independência, bem como sua inclusão social. Quando desenvolvidas para a utilização na escola, o objetivo destas tecnologias é garantir a sua aprendizagem (PELOSI, 2010; BRASIL, 2009).

Nos últimos anos têm aumentado o número de estudos sobre o Desenho Universal para a Aprendizagem (DUA), que se baseia no estudo das diferenças entre as formas de aprender e no desenvolvimento de ambientes de apoio à aprendizagem acessíveis para todos (HALL, MEYER; ROSE, 2012).

Hall, Meyer e Rose (2012) afirmam que os estudos mais recentes das neurociências demonstram que não existe um "aluno padrão", bem como são erros grotescos as classificações como estudante "esperto" ou "deficiente", já que as pesquisas mostram que as qualidades e habilidades dos estudantes não são estáticos ou fixos, eles se desenvolvem na interação com o ambiente. Estes estudos demonstram que a diversidade é a norma em um ambiente escolar, mesmo entre os grupos considerados "normais" e capazes de adquirir conhecimentos de um currículo "comum".

Neste sentido, a prática pedagógica que se desenvolve segundo os princípios do DUA atende a três princípios, relacionados a $o$ que se deseja ensinar e aprender, como aprendemos e demonstramos nossos conhecimentos, e por que devemos aprender. Respectivamente, estes princípios visam: apoiar a aprendizagem providenciando múltiplas formas de representação dos conteúdos; desenvolver estratégias de aprendizagem e estimular o engajamento com os conteúdos escolares, para gerar e manter a motivação.

A prática do DUA vem se constituindo através da busca pelo desenvolvimento de ambientes mais acessíveis, mais acesso à comunicação, informação e conhecimento, ou seja, visando dispor de um currículo acessível (conteúdos e formas de abordagem) a todos e adequado conforme as características e necessidades de cada um (FERNANDES, ANTUNES, GLAT, 2009; HALL, MEYER; ROSE, 2012) 
Segundo Fernandes, Antunes e Glat (2013) a escola foi construída e pensada para atender alunos que não apresentassem nenhum tipo de comprometimento, aqueles considerados popularmente como "normais". Com a entrada de alunos com deficiência, a ausência de acessibilidade, seja ela arquitetônica ou curricular (recursos e estratégias didático-pedagógicas), começou a ficar cada vez mais evidente mostrando que a garantia da matrícula e a mobilidade dentro do ambiente escolar não são suficientes para uma efetiva escolarização.

É necessário e urgente que a escola abandone o paradigma padronizador, que busca homogeneizar os estudantes mesmo quando tenta enquadrá-los em possíveis características de diagnósticos, e desenvolva práticas pedagógicas que considerem que alunos com diferentes tipos de desenvolvimento podem precisar de tempos variáveis para desenvolver habilidades e adquirir conhecimentos. Que suas atividades podem precisar de mínimas a consideráveis modificações e que diferentes instrumentos e recursos podem favorecer sobremaneira o processo de aprendizagem (desde um apoio para a preensão de lápis até um computador), ficando diante disso o desafio de pensar e elaborar estratégias pedagógicas que contemplem a diversidade e garantam a escolarização de todos (NASCIMENTO, CRUZ, BRAUN; 2016).

Em outras palavras, assim como as condições de locomoção de um estudante cadeirante precisam ser consideradas para que ele possa ter acesso e condições de utilização do mobiliário escolar, os elementos do currículo devem ser analisados em relação às características e necessidades do estudante com TEA. Os déficits na linguagem causados pelo transtorno, além das questões relacionadas aos interesses restritos e comportamento podem dificultar sua participação em atividades comuns no cotidiano escolar, demandando o desenvolvimento de recursos e estratégias que tornem sua participação mais efetiva. Permanecer sentado em uma cadeira escolar, por exemplo, pode ser uma tarefa difícil para esta criança ou adolescente.

Além disso, Czermainski, Bosa e Salles (2013) fizeram uma análise das publicações sobre avaliação neuropsicológica de crianças e adolescentes com autismo ocorridas na década de 2001 a 2011 nas bases de dados LILACS, PubMed e PsycINFO e verificaram que tem sido documentada uma "tendência de disfunções executivas nos TEA, envolvendo os componentes da inibição, do planejamento, da flexibilidade mental, da fluência verbal e da memória de trabalho" (CZERMAINSKI, BOSA, SALLES, 2013, p. 518). Estas dificuldades também devem ser consideradas durante o planejamento das práticas pedagógicas.

Além das características da síndrome clínica, com o objetivo de não reduzir a identidade do estudante a um diagnóstico, é importante que sejam consideradas as formas e estilos de aprendizagem de sua geração. Tal como constatado por Santarosa e Conforto (2015), Autor (2017) observou que os participantes da pesquisa demonstraram maior interesse pelos conteúdos Revista Interinstitucional Artes de Educar. Rio de Janeiro, V. 4, N.1- pág. 43 - 65 - (jan. - abr. de 2018): "Questões contemporâneas sobre a Educação Especial na Perspectiva da Educação Inclusiva" - 
curriculares apresentados no computador, comparando-se com as situações em que os mesmos eram apresentados no material didático disponibilizado pela Prefeitura.

\section{Novos tempos, novos perfis cognitivos}

Uma das coisas mais lastimáveis para um ser humano é ele não pertencer a seu tempo (FREIRE, 2003, p. 24)

Autor (2017) observou, através dos relatos dos responsáveis pelos estudantes participantes da pesquisa que eles utilizavam com habilidade, fora da escola, aparelhos como telefones celulares e tablets. A professora do Atendimento Educacional Especializado (AEE), quando entrevistada descreveu, também, uma experiência anterior, com uma aluna com TEA, que só começou a desenvolver a escrita a partir do uso do tablet:

\footnotetext{
Olha, é na verdade... a maioria... os nossos alunos que eu tenho atualmente, eles conseguem trabalhar com o material da sala de aula, igual aos outros colegas. Passei obrigatoriamente a necessitar com uma aluna só que... ((fala o nome da aluna)) que teve um momento, tem uns dois anos, que ela não escrevia, que não queria escrever, se recusava e aí teve um projeto do Instituto "tablet na escola" pros alunos autistas e aí nós recebemos um para ela. Então esse ano foi assim um ganho porque ela adora, adora joguinho de celular, adora tátil, adora computador, na casa é a coisa que chama a atenção dela, atividades que ela consegue se interessar, e aí nós passamos: tudo era colocado no tablet, ela fazia, depois a gente imprimia pra professora ter e pros responsáveis. Então foi um ano assim que a gente usou como coisa necessária. Os outros não. Às vezes a gente trabalha uma produção de texto, uma ortografia nos computadores, mas como uma atividade assim, diferente, entendeu? Mas não que tenha essa coisa de só não escrever ou por não conseguir, por não ter interesse, né? Graças a Deus eles conseguem trabalhar assim (AUTOR, 2017, p. 88).
}

Fica evidente no relato que a professora considera o recurso da Informática como algo "diferente" dos recursos comumente utilizados na escola, bem distante do conceito de instrumento cultural de amplo acesso na sociedade atual. Vygotski (1995) destaca a importância de se promover o desenvolvimento cultural da pessoa com deficiência, tendo em vista de que é na cultura que se desenvolvem as possibilidades de compensação dos déficits que precisa enfrentar. Além disso, é no meio social que primeiramente se desenvolvem as funções psicológicas superiores, em interação com pessoas mais experientes e com a mediação dos instrumentos culturais.

Assim como outras crianças e jovens de sua geração, estudantes com TEA parecem compreender a linguagem digital, navegando intuitivamente em seus dispositivos, onde 
interagem e aprendem com permanente motivação. Verificamos, portanto, que o computador contempla os três pilares do DUA descritos por Hall, Meyer e Rose (2012), pois oferece múltiplas formas de representação dos conteúdos, através da multimídia; favorece o desenvolvimento de estratégias de aprendizagem e estimula o engajamento com os conteúdos apresentados, por gerar e manter a motivação.

A professora do ensino regular, quando questionada se utilizava algum recurso tecnológico em sala de aula respondeu:

\begin{abstract}
Não. Porque eu não tenho um aluno que precise assim de um trabalho diferenciado. Porque você vê o ((cita o nome do aluno)) acompanha e entende tudo que eu falo. Ontem até a Cet Rio veio fazer um trabalho aqui e viu. Ele fala espanhol e sabe como é que ele está aprendendo a falar espanhol? Pela televisão... desenho em espanhol. Ele é inteligentíssimo, aquele menino. Ele conversou com a garota em inglês, ele não está num curso... só jogando pela internet ele sabe falar inglês; agora... (AUTOR, 2017, p.92)
\end{abstract}

É, no mínimo, contraditório, o fato de a escola não se apropriar desses instrumentos com o objetivo de enriquecer o processo de ensino-aprendizagem, sintonizando-os com a cultura contemporânea. Por outro lado, é importante considerar que a instituição escolar, na maior parte das vezes ainda é administrada por adultos que não têm familiaridade e consideram novas as tecnologias digitais, utilizando-as apenas como um acessório de luxo desenvolvido para projetos especiais - o que nos parece ser o caso do relato da professora. O currículo escolar, por este motivo, ainda é o mesmo desenvolvido para as gerações pré-digitais (AUTOR, 2013).

Em relação à familiaridade dos indivíduos com qualquer recurso tecnológico, Santaella (2009) destaca três grupos de usuários: o experto, que é aquele sujeito que encontra tudo o que necessita na rede; o leigo que por sua vez não domina, mas circula na rede, conseguindo fazer algumas buscas; e o novato, que é aquele que não conhece a rede e, portanto a utiliza de maneira muito limitada. Anderi e Toschi (2012) afirmam que geralmente os professores encontram-se no nível de leigo a novato, o que nos parece a ir de encontro com a afirmação de Autor (2013).

Além disso, Santaella (2009) analisou os diferentes perfis cognitivos desenvolvidos pelos leitores em função das tecnologias e suportes textuais predominantes na sociedade: livro, imprensa/tecnologias e massa, suportes digitais. A autora destaca que o uso da tecnologia contribui para a formação de um novo leitor uma vez que utiliza uma nova linguagem.

Os antigos textos, tradicionais, escritos em papel, bem como as pinturas, gravuras e mapas exigiram a formação de um leitor contemplativo, meditativo. Este era capaz de se concentrar na leitura, que é sequencial, mas que pode ser refeita pelo leitor, pois os textos podem buscados mais de uma vez, revisitados e ressignificados. A Revolução Industrial, através da 
impressão mecânica, do telégrafo e da fotografia fomentou uma nova linguagem escrita, mais dinâmica, como a dos jornais, cujos textos são mais curtos e efêmeros.

O perfil cognitivo do leitor se modificou, desenvolvendo-se, então, o leitor movente (SANTAELLA, 2009). Este leitor precisa de menos concentração, para focar nos inúmeros estímulos escritos que vê ao longo de seu dia nas grandes cidades, principalmente. Sua memória é, de certa forma, mais volátil: este leitor "precisa esquecer, pelo excesso de estímulos e falta de tempo para retê-los. Um leitor de fragmentos, leitor de tiras de jornal e fatias de realidade." (SANTAELLA, 2009, p. 29).

Com o surgimento do ciberespaço, a percepção do leitor sofreu novas modificações, tornando-o um leitor imersivo ou virtual. No ciberespaço, o texto não é sequencial, mas hipertextual, ou seja, vai se construindo segundo o desejo do leitor, que navega nos espaços virtuais, usando, como interface não mais um objeto manipulável, como o livro, mas uma tela na qual o texto eletrônico é lido com total liberdade de escolha, sem rotas pré-definidas. O perfil cognitivo do leitor imersivo é caracterizado pela e formado na interatividade. É um leitor cuja mente é distribuída, "capaz de realizar simultaneamente um grande número de operações. Observar, absorver, entender, reconhecer, buscar, escolher, elaborar e agir ocorrem em simultaneidade" (SANTAELLA, 2009, p. 182).

Considerando, portanto, o perfil desse novo aluno que a escola vem recebendo, que frequenta e circula pelo ciberespaço e se apropria rapidamente desta cultura, Autor (2017) buscou desenvolver atividades pertinentes aos conteúdos curriculares de Língua Portuguesa (Figura 1) e Matemática, utilizando o aplicativo PowerPoint 2013, que faz parte do pacote Office $^{l}$. Mesmo que não tenha sido, num primeiro momento criado com a finalidade de uma proposta educativa, seus slides permitem agregar recursos de áudio e imagens, além de disponibilizar diversas figuras, cores, fontes e tamanhos que podem ser muito úteis no ambiente escolar.

\footnotetext{
${ }^{1}$ Da Microsoft

Revista Interinstitucional Artes de Educar. Rio de Janeiro, V. 4, N.1- pág. 43 - 65 - (jan. - abr. de 2018): “Questões contemporâneas sobre a Educação Especial na Perspectiva da Educação Inclusiva” - 


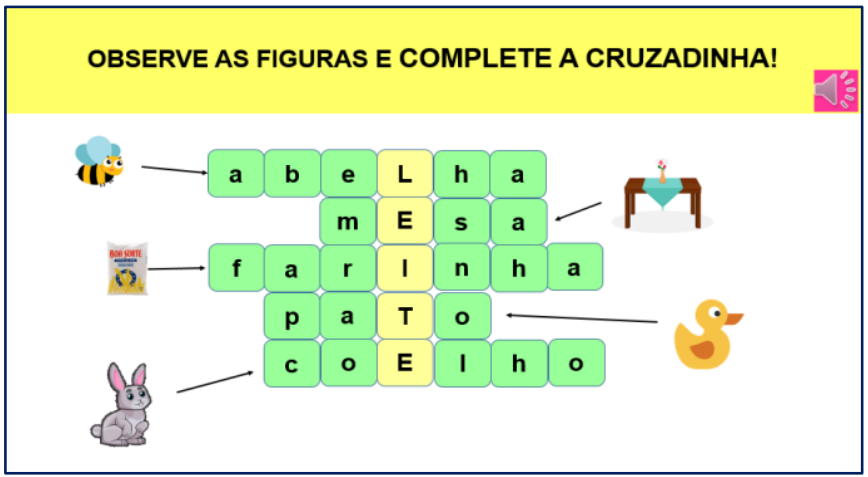

(Figura 1. Fonte: AUTOR, 2017, p. 128)

Essas atividades foram planejadas a partir das demandas observadas em sala de aula e das sugestões da professora do AEE. As trocas de ideias e planejamentos ocorriam antes, durante ou depois dos encontros da pesquisadora com os estudantes participantes da pesquisa, devido à impossibilidade de agendamento de reuniões com a professora, em função de sua rotina de trabalho.

Destacamos que antes de iniciarem as atividades, os alunos receberam algumas orientações sobre o uso do computador e das apresentações do PowerPoint, como a disponibilidade de um recurso de áudio para a leitura dos enunciados das questões, a utilização do mouse tanto para selecionar quanto para mover as figuras na tela e a utilização das teclas necessárias no teclado e disposição das letras.

Assim como Santarosa e Conforto (2015) constataram em sua investigação, observamos que a utilização do mouse se mostrou pouco intuitiva para esses alunos uma vez que requer maior controle e desenvolvimento da coordenação motora. Diante disso, eles optaram, na maioria das vezes, apenas pela utilização do toque dos dedos na tela.

Para a construção das atividades propriamente ditas, Autor (2017) seguiu as orientações do Guia Change para elaboração de textos acessíveis (CHANGE, s/d), que entre algumas normativas destaca para a parte escrita: utilizar frases curtas e claras, uma fonte limpa e que não seja desenhada com um tamanho mínimo de 14 pontos, usar tons pastéis para fundo de tela; e para as gravuras: as imagens devem representar aquilo que está escrito e serem preferencialmente alinhadas a esquerda da tela.

Foi disponibilizado para os alunos um notebook com tecnologia touchsceen que, assim como os smartphones e ipads, permite ser acessado apenas com o toque dos dedos na tela, uma vez que os computadores da escola estavam um pouco obsoletos e não disponibilizavam o PowerPoint 2013. 
Autor (2017) também utilizou atividades educativas e disponibilizadas em sites na internet (Figura 2) para trabalhar os conteúdos que estavam sendo abordados pela professora regente em sala de aula. Apresentados no computador, os mesmos conteúdos curriculares abordados em sala de aula pareciam despertar imediatamente e com maior intensidade o interesse dos estudantes.

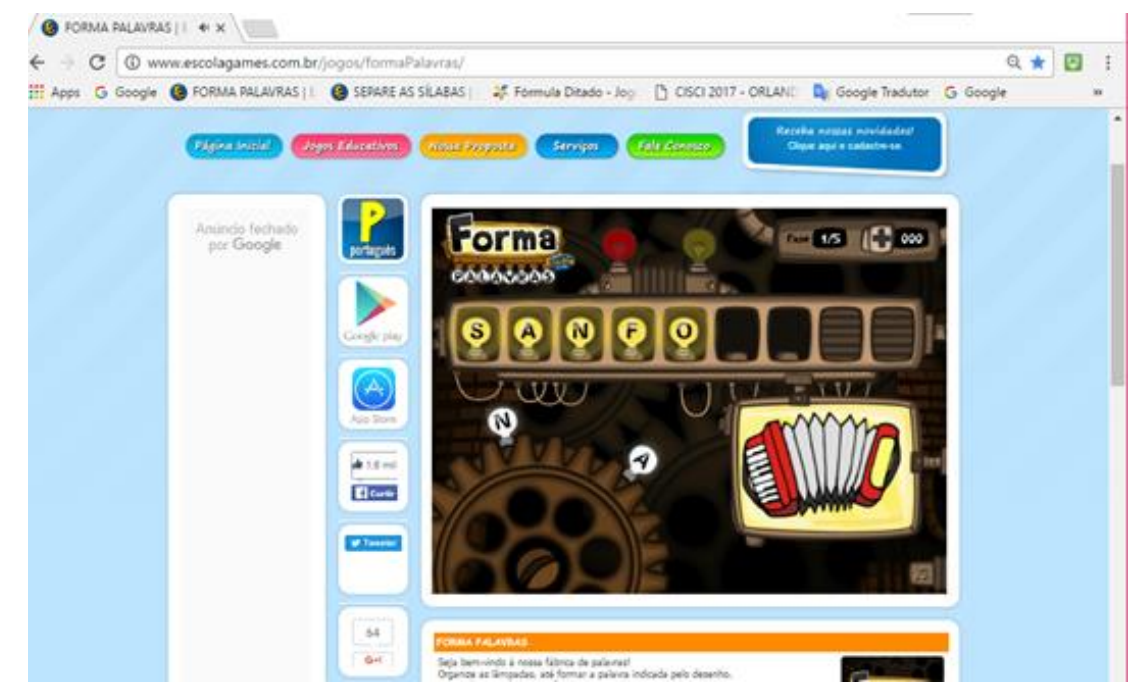

Figura 2: Jogo Forma PALAVRAS - www.escolagames.com.br

Na sociedade atual, o uso da Internet, além de servir para pesquisas, tem aproximado pessoas e transformado as relações humanas dando outro significado às mesmas. Neste ambiente, é possível observar, também, que meninas e meninos com TEA, que têm dificuldade de estabelecer uma relação olho a olho, conseguem interagir com seus pares através do computador como instrumento de mediação. "O ciberespaço constitui-se em um espaço público, um palco alternativo de relacionamento humano, favorecendo aprendizagens formais e informais" (AUTOR, 2013, p.79).

A rede de computadores apresenta um repositório inesgotável de conteúdos que, embora não tenham sido desenvolvidos com fins educativos, podem ser utilizados para realizar atividades e estreitar os vínculos. Autor (2017) relata que, em determinado encontro, João Grilo mostrou à pesquisadora alguns encartes de lojas que coleciona, bem como as escritas que produz, reproduzindo marcas comerciais (Figura 3). Depois, cantou para ela a música do comercial de uma rede de hortifrutigranjeiros. Em seguida, a pesquisadora acessou, com ele, o site da empresa, valorizando o interesse e o entusiasmo do menino. 


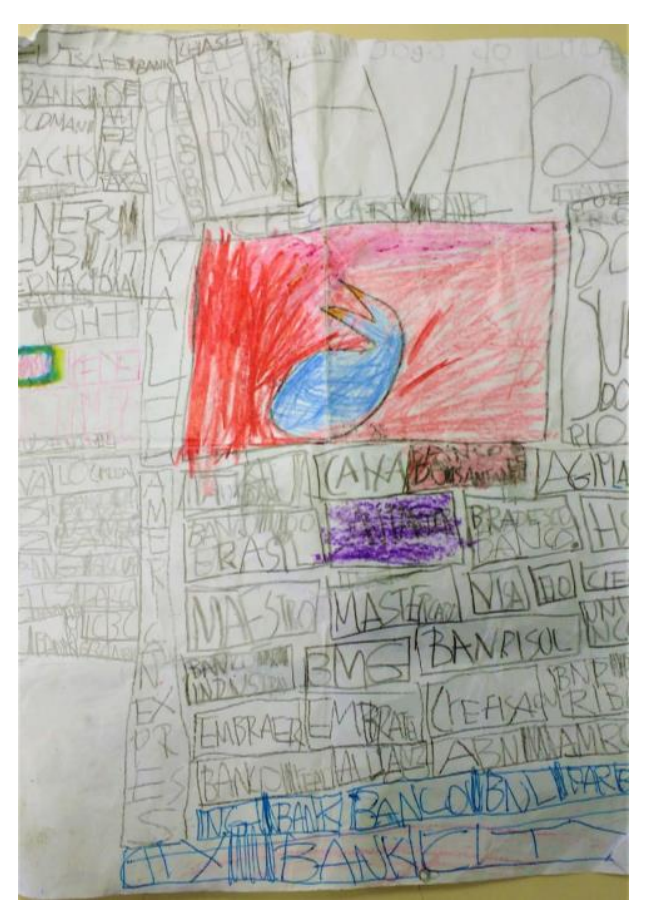

Figura 3: Marcas de empresas conhecidas - João Grilo

Alunos com autismo podem apresentar um raciocínio mais literal sobre aquilo que falamos, sua compreensão requer que o interlocutor seja mais objetivo naquilo que deseja. Para ambos os alunos as atividades foram ajustadas conforme a necessidade de cada um. $\mathrm{O}$ uso do computador favoreceu que estes ajustes individuais fossem feitos sem nenhuma dificuldade. Tal como proposto por Bersh (2006), pensamos em desenvolver um recurso que funcionasse como um equipamento personalizado, uma Tecnologia Assistiva para favorecer a realização das atividades acadêmicas. Por exemplo, um dos estudantes sentia-se incomodado com o som das atividades (efeitos sonoros de transição dos slides), por isso este foi desabilitado durante sua utilização. O outro participante, pelo contrário, não demonstrava desconforto algum e acessava tais recursos sonoros com frequência. Além disso, comandos simples, histórias curtas, cores atraentes, imagens explicativas e fontes aumentadas parecem ter despertado o interesse de ambos, favorecendo que permanecessem concentrados nas tarefas até concluí-las, o que não acontecia quando estavam diante do livro didático.

Azaleia (a professora da SRM), observando de longe, ao final da atividade (no computador) ficou animada dizendo que ele (o estudante) rendeu em trinta minutos o que não conseguia render a semana inteira, seja na sala de aula ou na SRM. (AUTOR, 2017, p. 119)

Procuramos disponibilizar histórias (que foram digitalizadas) e os enunciados das questões com letras em caixa alta (maiúscula) sem desenhos e com uma fonte limpa. Isso faz 
total diferença para alunos que apresentem uma dificuldade maior na aprendizagem da língua escrita.

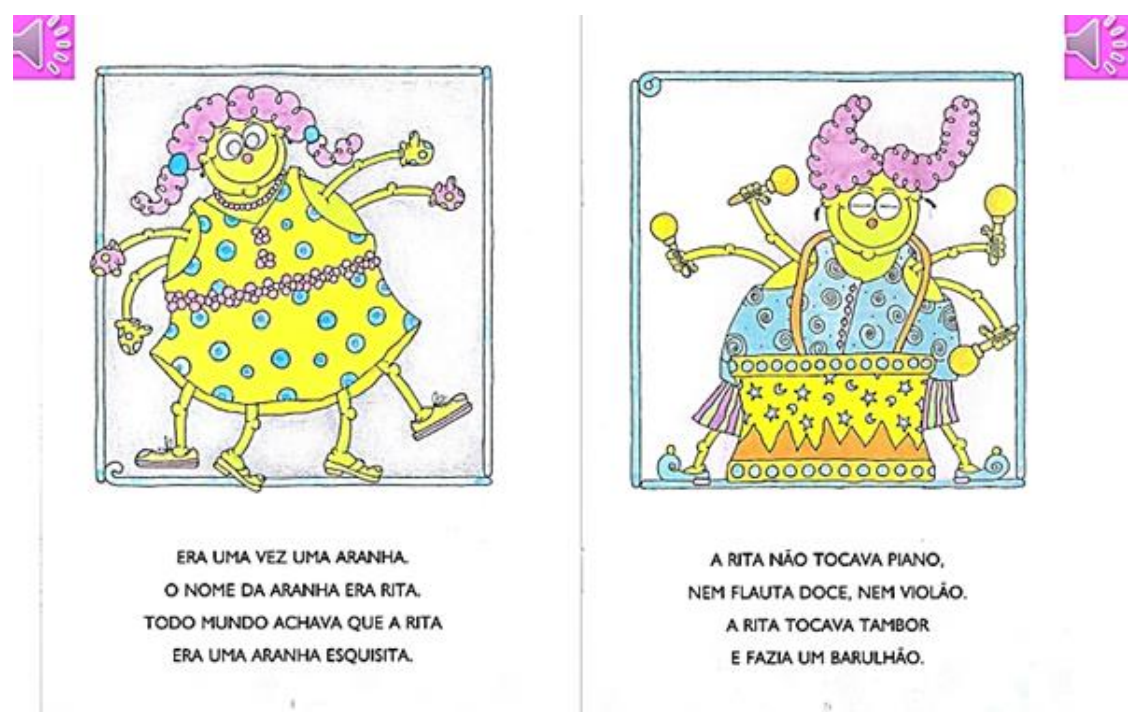

Figura 4: REIS, L. A esquisita aranha Rita. $3^{\mathrm{a}}$. ed. São Paulo: Paulinas, 2008. ${ }^{\text {iv }}$

O aluno que chega hoje à escola, e dentre os quais o com diagnóstico de autismo, não é um leitor contemplativo, ou seja, aquele que consegue se concentrar em lugar calmo e silencioso, tampouco o movente que segue a sequência de um livro ou do material didático disponível, ele é um leitor imersivo, que navega pelo ciberespaço em busca daquilo que é interessante para ele, seu comportamento pode parecer um tanto inquieto e seu olhar não direcionado, mas ele sabe exatamente aquilo que deseja conhecer.

Pesquisadora: Ele faz uso dessa tecnologia sozinho ou acompanhado por alguém?

Mãe: Sozinho.

Pesquisadora: Sabe fazer tudo?

Mãe: Sabe

Pesquisadora: Ele sabe escrever o nome que ele quer do vídeo que ele quer...

Mãe: Ele não sabe não. Ele aperta um botão lá que eu nem sabia que tinha ele aperta e fala: “- vídeo tal” Ai vai lá sozinho e consegue

Pesquisadora: Ah, ele usa o mecanismo de busca por voz?

Mãe: Isso. Eu nem sabia que tinha. E no dia que eu comprei o tablet. Ele ligou sozinho sem eu mexer e eu falei: “- caramba, ele sabe mexer mais do que eu." Ai ele mexeu, ele ligou, ele fez o que tinha que fazer e... sozinho. (AUTOR, 2017, p.93)

Houve, também, na pesquisa, o cuidado com o tipo e a disposição das imagens, de forma que estas ilustrassem o texto de forma clara e objetiva, dando apoio ao raciocínio do estudante. A Figura 5 mostra uma atividade de matemática desenvolvida a partir do livro paradidático (REIS, 2008). Além de o fato da contextualização favorecer a associação de ideias, tornando o problema 
mais "concreto", foram utilizados recursos gráficos (riscos sobre as bolas que deveriam ser retiradas do conjunto) para dar ideia da operação descrita (subtração).

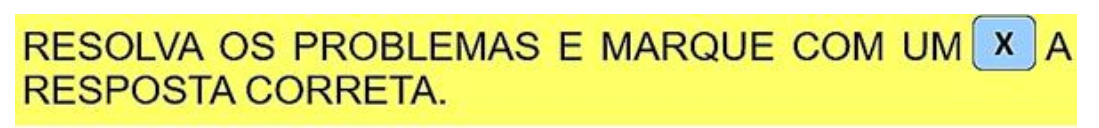

\section{RITA TINHA 15 BOLAS 00000000000000 ELA PERDEU $5000000000 R$ QRQR}

COM QUANTAS BOLAS RITA FICOU?

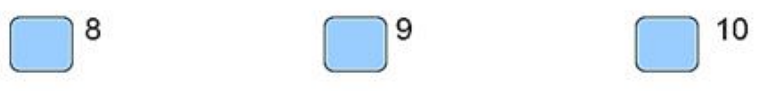

Figura 5: Exercício de matemática

Por outro lado, Autor (2017) observou que nem sempre a imagem contribuiu para a compreensão do texto podendo, até mesmo confundir a criança. Na Figura 4, por exemplo, a pesquisadora observou que esse tipo de exercício não contribuiria para o aprendizado do aluno e que nesse caso teria sido melhor pedir para o aluno somar as partes para encontrar o resultado, uma vez que, além de ter muita informação no slide a tendência do aluno das séries iniciais do Ensino Fundamental é marcar a imagem semelhante ao modelo. O enunciado do problema também é muito complexo para a faixa etária. A ideia de "quantos faltam para" envolve uma operação de subtração que não é apresentada de forma explícita.

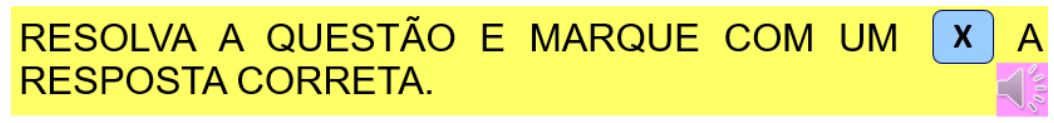

QUANTAS BOLAS FALTAM PARA COMPETAR 9?

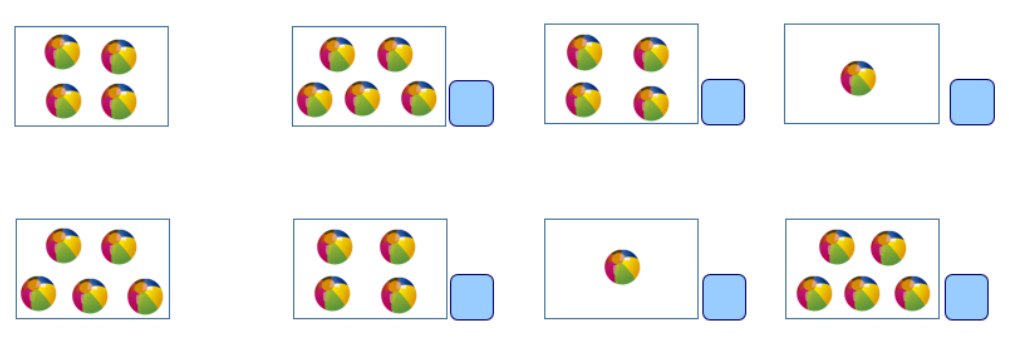

Figura 5: Exercício de matemática

Autor et al. (2017) destacam que alunos com autismo demonstram mais interesse e compreensão quando os textos estão claros, com frases objetivas, dispondo do uso de imagens e 
com conteúdos mais “concretos”. Foram feitas adaptações do material didático utilizado pela turma, seguindo as orientações para a elaboração de textos acessíveis e com as vantagens dos recursos do computador, como a interatividade e as possibilidades de customização de acordo com as necessidades e interesses de cada estudante. A Figura 6 mostra a atividade inicial e a Figura 7 representa a elaborada no PowerPoint, contextualizada a partir de um livro paradidático.
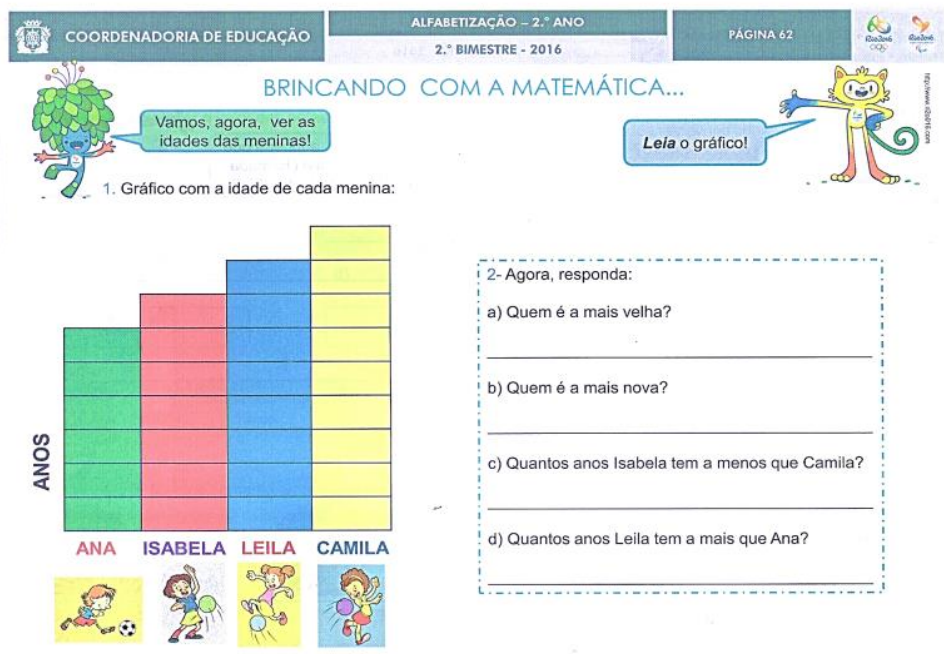

Figura 6: Atividade apostila $\mathrm{SME} / \mathrm{RJ}-2^{\circ}$. ano/2 ${ }^{\circ}$. bimestre/pag. 62

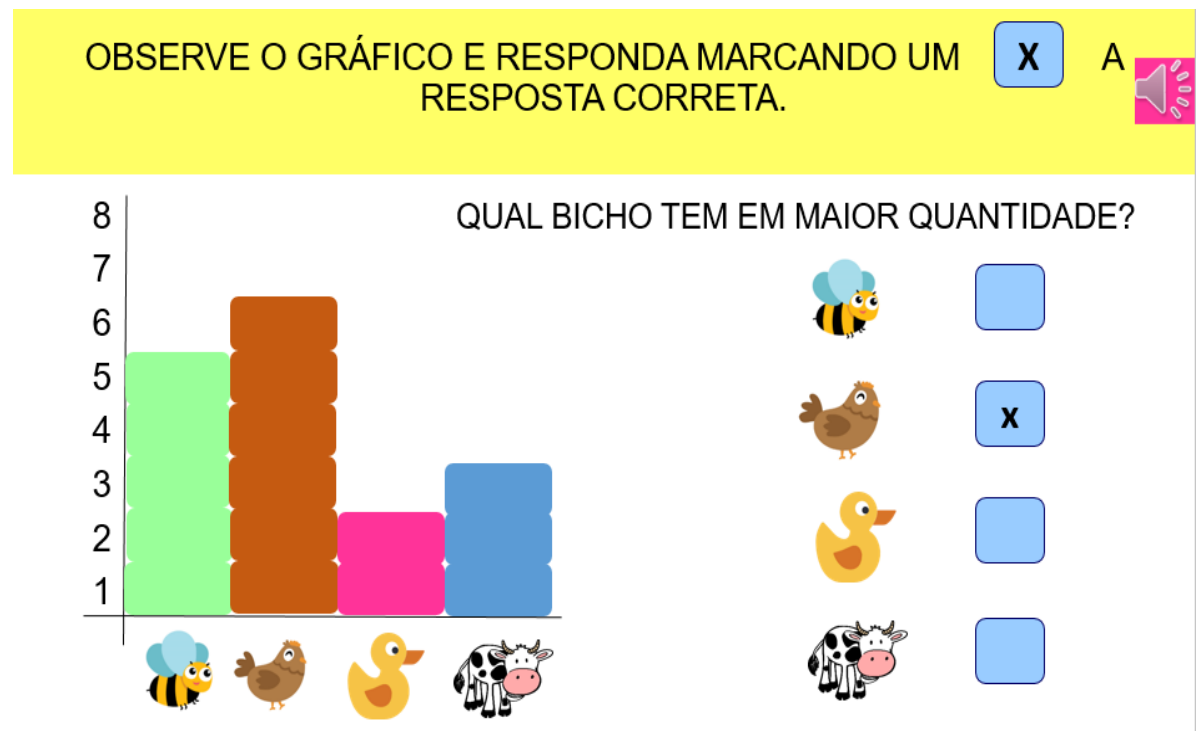

Figura 7: Atividade de matemática da história 'O bolo fofo' - realizada por um dos participantes da pesquisa

As dificuldades relacionadas ao comportamento, observadas em sala de aula na fase inicial da pesquisa, ocorreram apenas em um dos encontros da segunda fase. É provável que o 
fato de permanecerem interessados e atentos às atividades realizadas no computador tenha favorecido uma melhora no comportamento de um dos estudantes participantes da pesquisa.

Os comportamentos considerados difíceis (se jogar na sala, jogar materiais no chão, ficar rodopiando, ser agressivo, por exemplo) não desapareceram durante o horário escolar, mas foram minimizados principalmente nesses encontros, pois quase não os vimos no momento em que interagia com o equipamento. Houve apenas um dia em que Chicó apresentou comportamento agressivo (jogando livros e materiais ao chão, correndo pelos corredores, fazendo xixi no banheiro em lugar inadequado) e foi preciso suspender a sua participação na atividade para preservamos a sua integridade e a dos demais (AUTOR, 2017, p. 122).

Foi interessante observar que, além de realizar as atividades propostas, os estudantes experimentavam fazer modificações nas mesmas, "personalizando-as", explorando os ícones e recursos do programa, adotando uma postura ativa. Na Figura 8, por exemplo, além de marcar a resposta correta, o estudante Chicó modificou o formato da caixa correspondente à opção.

\section{MARQUE COM UM $\mathbf{x}$ A RESPOSTA CORRETA.}

1. QUAL O NOME DAARANHA?

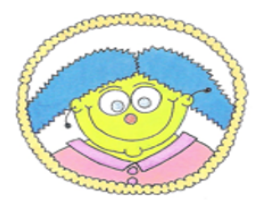

MARIA

RITA

BIA

Figura 8: Atividade de interpretação de texto da história 'A esquisita aranha Rita' - realizada por Chicó

Fazer TA na escola é buscar, com criatividade, uma alternativa para que o aluno realize o que deseja ou precisa. É encontrar uma estratégia para que ele possa "fazer" de outro jeito. É valorizar o seu jeito de fazer e aumentar suas capacidades de ação e interação, a partir de suas habilidades. É conhecer e criar novas alternativas para a comunicação, escrita, mobilidade, leitura, brincadeiras e artes, com a utilização de materiais escolares e pedagógicos especiais. É a utilização do computador como alternativa de escrita, fala e acesso ao texto. É prover meios para que o aluno possa desafiar-se a experimentar e conhecer, permitindo assim que construa individual e coletivamente novos conhecimentos. É retirar do aluno o papel de espectador e atribuir-lhe a função de ator (BERSH, 2006, p. 281).

Por fim, destacamos a questão da afetividade, do engajamento com as atividades e da valorização, pelos estudantes, da mediação da pesquisadora na realização das tarefas propostas. Estes fatores, que são de inquestionável importância no processo de ensino-aprendizagem de 
qualquer estudante, tornam-se ainda mais relevantes quando, em função do TEA, os aprendizes apresentam dificuldades nas habilidades sociais.

Autor (2017) relata que, ao longo do desenvolvimento da pesquisa, os estudantes apresentaram, cada vez com maior frequência, comportamentos de interação com ela, como trazer materiais para lhe mostrar, solicitar que compartilhasse uma leitura, ou até mesmo se aconchegar em seu braço para ler/ouvir uma história. Neste sentido, o uso do computador, com a intencionalidade de desenvolver uma prática pedagógica, pode promover interação e autonomia, e não isolamento e alienação.

\section{Considerações finais}

As deficiências e outras diferenças significativas de aprendizagem e desenvolvimento não são, em si, obstáculos para o processo de aprendizagem, visão que fundamentou, durante décadas, o ensino segregado em classes ou escolas especiais. Ao contrário, a presença de estudantes com estas características nas salas de aula comuns evidencia o que vem sendo ratificado pelos estudos das neurociências: que ninguém aprende da mesma forma e que é preciso ter uma postura ativa para aprender.

O uso do computador na prática pedagógica desenvolvida (AUTOR, 2017) pareceu atender aos princípios do Desenho Universal para a Aprendizagem, pois estimulou o reconhecimento e a associação de ideias, favoreceu o desenvolvimento de estratégias e promoveu o engajamento afetivo com o contexto.

Desta forma, tais atividades certamente seriam adequadas para todos os estudantes e não somente para os que têm TEA ou dificuldades na aprendizagem. Questionamos se as dificuldades que estes apresentam, como em permanecer por horas sentados ouvindo uma aula expositiva, escrevendo ou copiando do quadro não são compartilhadas, em menor grau pelos demais estudantes da atual geração, leitores imersivos que interagem ativamente com os dispositivos digitais e são solicitados a permanecer passivamente ouvindo, lendo ou copiando na escola.

Concluímos que as modificações necessárias ao currículo, para que este seja acessível a todos, devem começar pela ampliação de sua concepção no cotidiano escolar, para que deixe de ser compreendido, na prática, como disciplinas e conteúdos, e passe a ser visto em sua totalidade, como contexto de múltiplas relações e representações.

A acessibilidade envolve, também, a construção de "caminhos" para que os estudantes possam desbravar seu meio cultural com suas próprias pernas, aprendendo os conteúdos 
socialmente relevantes, com a mediação do professor e colegas. Optamos pela metáfora dos "caminhos" e não nos referimos a "pontes" porque o currículo não deve ser comparado a um lugar onde o estudante deve chegar, mas a trajetos que vêm sendo construídos pelas gerações. Enquanto o professor incentiva e medeia a caminhada, promove a imersão cultural, favorecendo que todos aprendam e se desenvolvam, produzindo também a cultura de seu tempo.

\section{Referências}

APA - AMERICAN PSYCHIATRIC ASSOCIATION. Manual Diagnóstico e Estatístico de Transtornos Mentais. Porto Alegre: ArtMed, 2014

DSM-IV. Manual diagnóstico e estatístico de transtornos mentais. Trad. D. Batista, $4^{\mathrm{a}}$ ed. Porto Alegre: Artes Médicas Sul, 2000.

Diagnostic and Statistical Manual of Mental Disorders (third edition). 1980. Disponível em: http://displus.sk/DSM/subory/dsm3. pdf. Acesso em: 24 set. 2016.

BRASIL. Lei no 9.394, de 20/12/1996. Dispõe sobre a Lei de Diretrizes e Bases da Educação Nacional. Disponível em: http://portal.mec.gov.br/arquivos/pdf/ldb.pdf Acesso em: 12 nov. 2015.

. Lei 12.764, de 27/12/2012. Institui a Política Nacional de Proteção dos Direitos da Pessoa com Transtorno do Espectro Autista; e altera o § 3o do art. 98 da Lei no 8.112, de 11 de dezembro de 1990. Disponível em http://www.planalto.gov.br/ccivil_03/_ato20112014/2012/lei/112764.htm. Acesso em 23 dez. 2013.

Decreto n. 5.296 de 02 de 02/12/2004. Regulamenta as Leis $n^{\underline{o s}} 10.048$, de 8 de novembro de 2000, que dá prioridade de atendimento às pessoas que especifica, e 10.098, de 19 de dezembro de 2000, que estabelece normas gerais e critérios básicos para a promoção da acessibilidade das pessoas portadoras de deficiência ou com mobilidade reduzida, e dá outras providências. Disponível em: http://www.planalto.gov.br/ccivil_03/_ato20042006/2004/decreto/d5296.htm Acesso em: 05 ago. 2017.

. Subsecretaria Nacional de Promoção dos Direitos da Pessoa com Deficiência. Comitê de Ajudas Técnicas. Tecnologia Assistiva - Brasília: CORDE, 2009. 138 p. Disponível em: http://www.pessoacomdeficiencia.gov.br/app/sites/default/files/publicacoes/livro-tecnologiaassistiva.pdf Acesso em: 01 jan. 2017.

BRAUN, P. A pesquisa-ação: aspectos conceituais, aplicação e implicações em investigações sobre educação especial. In: NUNES, L. R. d'O. P. (org.). Novas trilhas no modo de fazer pesquisa em Educação Especial. São Carlos: Ed. Marquezine \& Manzini: ABPEE, 2014, p.89101.

CHANGE. How to make information accessible. A guide to producing easy read documents. Disponível em: http://www.ageingwellinwales.com/Libraries/Documents/how-to-makeinformation-accessible.pdf Acesso em: 15 fev. 2016 
CZERMAINSKI, F. R.; BOSA, C. A.; SALLES, J. F. Funções executivas em crianças e adolescentes com transtorno do espectro do autismo: uma revisão. Psico, v. 44, n. 4, p. 518-25, out./dez., 2013. Disponível em:

http://revistaseletronicas.pucrs.br/ojs/index.php/revistapsico/article/view/11878/10844 Acesso em: 18 jan. 2016.

CORREIA, G. B. Educação especial e currículo: das adaptações curriculares a acessibilidade curricular. Anais do XI ANPED Sul. Curitiba: UFPR. Disponível em: http://www.anpedsul2016.ufpr.br/wp-content/uploads/2015/11/eixo22_GILVANE-BELEMCORREIA.pdf Acesso em: 10 ago. 2017.

AUTOR Ambiente virtual de aprendizagem para letramento de alunos com deficiência intelectual. Tese (doutorado em Educação). 246 páginas. Programa de Pós-Graduação em Educação (PROPED). Universidade do Estado do Rio de Janeiro. 2013

AUTOR et. al. Autismo e educação inclusiva: mediação pedagógica na era tecnológica. Portugal: Whitebooks, 2017.

EFGEN, A. P. S. Educação Especial e Currículo Escolar: Possibilidades nas práticas pedagógicas cotidianas. 2011. 221 f. Dissertação (Mestrado em Educação) - Universidade Federal do Espírito Santo, Vitória, 2011. Disponível em:

http://repositorio.ufes.br/bitstream/10/2297/1/tese_5671_.pdf Acesso em: 10 ago. 2017.

FERNANDES, E. M.; ANTUNES, K. C. V.; GLAT, R. Acessibilidade ao currículo: prérequisito para o processo ensino-aprendizagem de alunos com necessidades educacionais especiais no ensino regular. In: GLAT, R. (org.). Educação inclusiva: cultura e cotidiano escolar. Rio de Janeiro: 7 Letras, 2013, p. 53-61.

FERREIRA, A.B.H. Miniaurélio Século XXI: O minidicionário da língua Portuguesa. $4^{\mathrm{a}}$ ed. Rio de Janeiro: Nova Fronteira, 2001.

FREIRE, Paulo. Sobre Educação. Vol. 2. $3^{\text {a }}$.ed. São Paulo: Paz e Terra, 2003.

GLAT, Rosana. Somos iguais a vocês: depoimentos de mulheres com deficiência mental. 2. ed. Rio de Janeiro: 7Letras, 2009.

HALL, T. E; MEYER, A.; ROSE, D. H. Universal Design for Learning in the classroom. Practical applications. New York: The Guilford Press, 2012

INSTITUTO DE TECNOLOGIA SOCIAL; MICROSOFT. Tecnologia assistiva nas escolas: recursos básicos de acessibilidade sócio-digital para pessoas com deficiência, 2008. Disponível em:http://www.ufjf.br/acessibilidade/files/2009/07/Cartilha_Tecnologia_Assistiva_nas_escolas_ -_Recursos_basicos_de_acessibilidade_socio-digital_para_pessoal_com_deficiencia.pdf Acesso em 02 ago. 2017.

JESUS, D. M. de. O que nos impulsiona a pensar a pesquisa-ação colaborativo-crítica como possibilidade de instituição de práticas educacionais mais inclusivas. In: BAPTISTA, C. R. et al. (org.) Educação especial: diálogo e pluralidade. Porto Alegre: Ed. Mediação, 2010, p. 13959. 
LEVY, P. Cibercultura. Trad. Carlos Irineu da Costa. 2a . ed. São Paulo: Editora 34.

MOREIRA, A. F. B.; CANDAU, V. M. Currículo, conhecimento e cultura. In: Indagações sobre o currículo do Ensino Fundamental - Salto para o Futuro. Brasília: TVEscola/SEED/MEC, 2007 Disponível em:

http://cdnbi.tvescola.org.br/resources/VMSResources/contents/document/publicationsSeries/142 6101400598.pdf\#page=20 Acesso em: 10 ago. 2017

OLIVEIRA, E. MACHADO, K. S. Adaptações curriculares: caminho para uma Educação Inclusiva. In: GLAT, R. (org.). Educação inclusiva: cultura e cotidiano escolar. $2^{\mathrm{a}} \mathrm{ed}$. Rio de Janeiro: 7 Letras, 2013, p. 36-52.

PELOSI, M. B. A tecnologia assistiva como facilitadora do processo de ensino e aprendizagem: uma parceria do Instituto Helena Antipoff e a Terapia Ocupacional da UFRJ. In: ARANHA, G.; SHOLL-FRANC, A. (orgs) Caminhos da Neuroeducação. Rio de Janeiro: Ciência da Cognição, 2010. Disponível em: https://sites.google.com/site/tecnologiaassistivacombr/artigos-cientificos Acesso em: 02 ago. 2017.

AUTOR. Recursos tecnológicos: estratégias e perspectivas pedagógicas para alunos com transtorno do espectro do autismo. Dissertação (Mestrado em Ensino de Educação Básica). Programa de Pós-Graduação de Ensino em Educação Básica. Universidade do Estado do Rio de Janeiro. 2017

REIS, L. A esquisita aranha Rita. $3^{\text {a }}$. ed. São Paulo: Paulinas, 2008.

SANTAELLA, L. Navegar no ciberespaço: o perfil cognitivo do leitor imersivo. $3^{\text {a }}$. ed. São Paulo: Ed. Paulus, 2009.

SANTAROSA, L. M. C.; CONFORTO, D. Tecnologias móveis na inclusão escolar e digital de estudantes com transtornos de espectro autista. In: Revista Brasileira de Educação Especial Marília, v. 21, n.4, 349-66, 2015. Disponível em: http://www.scielo.br/pdf/rbee/v21n4/14136538-rbee-21-04-00349.pdf Acesso em 30 mar. 2016.

VYGOTSKI, L. S. Obras escogidas V-Fundamentos de defectologia. Madri: Ed. Machado, 1995. 
${ }^{i}$ Doutora em Educação. Professora Adjunta da Universidade do Estado do Rio de Janeiro (UERJ) - Instituto de Aplicação Fernando Rodrigues da Silveira e do Programa de Pós-graduação de ensino em educação básica (PPGEB).

ii Mestre pelo Programa de Pós-graduação de ensino em educação básica (PPGEB/UERJ).Professora da Rede Municipal de Educação de Duque de Caxias.

iii Para preservar suas identidades, os estudantes receberam na pesquisa os nomes fictícios de João Grilo e Chicó, as professoras foram chamadas de Rosa e Azaleia e as mães dos alunos foram identificadas como Iara e Vitória-régia.

iv A reprodução das imagens deste livro foi autorizada pela autora da obra e pela editora Paulinas. 